\title{
PERCEPTION OF SELF-CARE AND SELF-CARE PRACTICE OF DIABETIC PATIENTS ATTENDING SELECTED HOSPITALS IN OYO STATE, NIGERIA
}

\author{
Aina Modupe A. ${ }^{1}$ and Agbede Catherine O. (Ph.D) ${ }^{2}$ \\ ${ }^{1}$ Department of Public Health, Babcock University, Ilishan-Remo, Ogun State, Nigeria \\ Email address; dupeaina2002@yahoo.com \\ ${ }^{2}$ Department of Public Health, Babcock University, Ilishan-Remo, Ogun State, Nigeria \\ Email: agbedec@ babcock.edu.ng
}

Cite this article:

Aina M.A., Agbede C.O. (2021), Perception of Selfcare and Self-care Practice of Diabetic Patients Attending Selected Hospitals in Oyo State, Nigeria. International Journal of Public Health and Pharmacology 1(2), 50-59. DOI: $10.52589 /$ IJPHPXKALSFE8.

\section{Manuscript History}

Received: 14 July 2021

Accepted: 7 Aug 2021

Published: 21 Aug 2021

Copyright $(2020$ The Author(s). This is an Open Access article distributed under the terms of Creative Commons AttributionNonCommercial-NoDerivatives 4.0 International (CC BY-NC-ND 4.0 ), which permits anyone to share, use, reproduce and redistribute in any medium, provided the original author and source are credited.
ABSTRACT: Patients with diabetes require continuous selfcare practice as poor self-care results in complications. This study assessed the perception of self-care and self-care practice of diabetic patients attending selected hospitals in Oyo State, Nigeria. An institutional-based cross-sectional study was employed and a total of 120 diabetic patients were selected using a systematic random sampling technique. Pretested, structured, and interview administered questionnaires were used for data collection. The collected data were analysed using IBM SPSS version 23 to generate descriptive (Mean and standard deviation) and inferential (Chi-square and correlation) statistics. The respondents had a mean perception score of 30.68 \pm 7.56 . Majority 113(94.2\%) of the respondents had poor self-care practices. Respondents' perception was significantly correlate with patient physical activity $(r=0.184 ; p=0.004)$; healthy eating $(r=-0.24 ; p=0.026) ;$ glucose monitoring $(r=0.319 ; p=0.000)$; compliance with medication $(r=0.438 ; p=0.00)$; risk reduction $(r=0.229 ; p=0.012)$ However, patient perception is not correlated with foot care $(r=0.052 ; p=0.575)$. Patient's perception of diabetes is a key determinant of self-care. It is recommended that psycho cognitive interventions are developed to help patients practice the recommended self-care practices.

KEYWORDS: Diabetes, Perception, Self-care, Oyo State 


\section{INTRODUCTION}

Diabetes is one of the leading global public health concerns, imposing a heavy global burden on public health as well as socio-economic development. Although incidence has started to decrease in some countries, the prevalence of diabetes has increased in recent decades in most developed and developing countries (Patterson, et al., 2019). The International Diabetes Federation (IDF) have estimated that 463 million adults are currently live with diabetes worldwide in the year 2019 with a projected increase to 578 million by 2030 and 700 million by the year 2045 if no effective prevention methods are adopted (IDF, 2019).

Currently, sub-Saharan Africa is estimated to have 20 million people with diabetes, about $62 \%$ are not diagnosed and the number is expected to reach 41.4 million by 2035 or an increase of 109.1\% (World Health Assembly, 2013). In sub-Saharan Africa, Nigeria has the highest number of people with diabetes with an estimated 3.9 million people of the adult population aged 20-79-year-old (Dahiru, et al., 2016). The current prevalence of Diabetes among adults aged 20-69 years in Nigeria is reported to be 3\% (IDF, 2019). A study conducted in Ibadan Oyo State by Odeyinka and Ajayi (2017), revealed diabetes in Ibadan Oyo state has a prevalence of 3.4\%. Another study conducted by Rasaki, et al., (2017) to assess the prevalence of diabetes and pre-diabetes and associated risk factors among indigenes of Oke-Ogun geopolitical zone of Oyo State showed that the prevalence of diabetes in this study was $4.6 \%$ ( $93.7 \%$ female, $6.3 \%$ male) and pre-diabetes $6.0 \%$ ( $85.0 \%$ female and $15.0 \%$ male).

Worldwide a radical increment in prevalence of diabetes was related to an increased prevalence of modifiable risk factors such as unhealthy dietary patterns, lack of physical exercise, excess body weight, and sedentary lifestyle (Kolb\& Martins, 2017). These factors are highly responsible for the current increasing incidence of diabetes (Oluma, et al., 2020).Diabetes's self-care behaviours are a dynamic and cognitive practice that includes healthy eating, physical activity, monitoring blood glucose, compliance with medication, foot care and risk reduction behaviour towards the disease (American Diabetes Association Standards of Medical Care in Diabetes, 2009) All these seven behaviours positively correlate with good glycemic control, reduction of complications and improvement in quality of life (Shrivastava,et al., 2013). Many studies have reported poor self-care behaviours (Mogre, et al., 2017; Elsous, et al., 2017; Aminde, et al., 2019). Poor self-care behaviours and medications could lead to uncontrolled diabetes and subsequently the development of diabetes complications (Kassahun, et al., 2016).

It has been observed that some diabetic patients who were seen on regular follow-up in the clinic in Oyo State still came down with poor glycaemic control despite the treatment received this is a problem that called for close attention. Self-management among people living with diabetes is still very poor and non-adherence to clinical regimen is rampant and greatly influenced by cultural beliefs.A better understanding of factors contributing to poor self-care behaviour is necessary to develop effective adherence-enhancing interventions. This study therefore assessed the perception of self-care and self-care practice of diabetic patients attending selected hospitals in Oyo State, Nigeria. 


\section{MATERIAL AND METHODS}

\section{Design and Sample}

This is an Institutional-based cross-sectional design. Persons living with type 2 diabetes and receiving health care at Adeoyo teaching hospital, State hospital Saki, Moniya general hospital and Adegbite cottage health clinic in Oyo state, constituted the population for the study. A total of one hundred and twenty (120) participants were selected using systematic sampling techniques. The inclusion criteria were those aged 20 years and above, have been living with diabetes for a year or more, and willingness to give informed consent to participate in the study.

\section{Measures}

\section{Self-care practices questionnaire}

This is an 11-item self-report questionnaire which consists of six domains of diabetes self-care practices. These domains include healthy eating measured by four items (e.g. I include more servings of fruits and vegetables in diet), physical activity measured by fours items (e.g. I skip planned physical activity), monitoring blood glucose measured by five items (e.g. I regularly do a self-blood test to monitor my blood sugar level), foot care measured by five items (e.g. I inspect my foot daily), risk reduction behaviour measured by five items (e.g. as long as my blood sugar is in check, I still drink alcohol/smoke), and the final subscale which is compliance with medications was measured by five item (e.gI only take my medication when my blood sugar level is high). These subscales were measured on a 3-point Likert response format ranging between 0 and 3 . The mean scores on the items were computed to obtain the subscale scores for each domain. The sum of the subscales creates a composite score for total self-care. An overall internal consistency value $(\alpha)$ of .0 .90 was obtained for this study.

\section{Perception of Self-care}

Perception of respondents' of self-care consist of twenty-six (26) questions to be measured on a 78-point rating scale of Strongly Agree (SA), Agree (A), Disagree (D) and Strongly Disagree (SD). For the negatively constructed questions, strongly agree (SA) was scored 0, Agree (A) was scored 1, Disagree (D) was scored 2 and Strongly Disagree (SD) was scored 3. For the positively constructed questions, strongly agree (SA) was score 3, Agree (A) was score 2, Disagree (D) was score 1 and Strongly Disagree (SD) was score 0. A Cronbach alpha of .83 was found for the present study.

\section{Procedure}

Ethical clearance was obtained by Babcock University Health Research and Ethic Committee. The clearance letter and the proposal for this study were sent to the medical director of the selected hospitals to seek permission to use the hospitals as the study site. After the medical director of the hospital gave their permission for the data collection, the patients receiving diabetes care at the outpatients department of the diabetes unit diagnosed with type diabetes were approached. The objectives of the study were explained to the patients and those who agreed to participate in the study gave consent. The questionnaires were self-administered or interviewer-administered depending on the level of education of the participants. It took an average of $30 \mathrm{~min}$ for a questionnaire to be completed. The completed questionnaires were retrieved from the participants on the same day for coding and analysis. The entire data 
collection was May, 2021. No incentive was provided as participation in the study was voluntary.All the ethical guidelines concerning the use of human participants in research (e.g. informed consent, confidentiality, privacy, no harm, voluntary participation etc.) were strictly adhered to in the research process.

\section{Data analyses}

Data was analyzed using the Statistical Package for the Social Sciences version 21.0 for Window (IBM SPSS). To determine the self-care related knowledge and self-care practices, two analyses were conducted. First, descriptive statistics was to generate frequency tables, mean and standard deviation. Secondly, the Pearson-moment correlation coefficient (r) was conducted to examine the relationship between the self-care practice and its domains (healthy diet, physical activity, monitoring blood glucose, foot care, risk reduction behaviour and compliance with medications), and self-care related knowledge while, chi-square was used to test the relationship between perception and socio-demographic characteristics. All test conducted were two-tailed and held statistical significance at $p<.05$

\section{RESULTS}

\section{Respondents Perception of Self-care and Relationship with Socio-demographic Characteristics}

Table 1 showsrespondent's perception of self-care behaviour measured on a 78-point rating scale, showed a mean score of $30.68 \pm 7.56$. Respondents' perception of self-care behaviour was further categorized into low (0-26) moderate (27-52) and high (53-78). Most 85(70.8\%) of the respondents had moderate perception of self-care behaviour while about a quarter $35(29.2 \%)$ of the respondents had low perception of self-care behaviour.

There is a significant relationship between respondent's gender $\left(\mathrm{X}^{2}=8.63 ; p=0.003\right)$; educational attainment $\left(X^{2}=15.49 ; p=0.001\right)$; ethnicity $\left(X^{2}=17.82 ; p=0.00\right)$, occupational status $\left(\mathrm{X}^{2}=29.36 ; p=0.00\right)$; family history of diabetes $\left(\mathrm{X}^{2}=6.36 p=0.01\right)$ and perception of selfcare. While there was no significant relationship between respondents age $\left(\mathrm{X}^{2}=5.74 ; p=0.45\right)$ and perception of self-care (See table 2 below).

\section{Respondents Self-Care Practices}

Regarding self-care practice domains of diabetic patient, majority of the respondents $114(95 \%)$ had low physical activities, most of the respondents $102(85 \%)$ had unhealthy eating habits, majority of the respondents $116(96.7 \%)$ had low monitoring of blood glucose, most of the respondents $87(72.5 \%$ ) had low compliance with medication, majority of the respondents had low risk reduction behaviour and more than half of the respondents $70(58.3 \%)$ had low foot care behaviour. Overall majority of the respondents $113(94.2 \%)$ had low self-care practice (See, table 3). The result of the correlation analysis showed a relationship between perception of self-care and self-care practice of diabetic patients $(\mathrm{r}=0.40 ; \mathrm{p}=0.000)$. These suggest that when patients perceive diabetic to be threatening, they engage in self-care practice. The result further showed that patient perception of the illness was significantly correlate with patient physical activity $(\mathrm{r}=0.184 ; p=0.004)$; health eating $(\mathrm{r}=-0.24 ; \mathrm{p}=0.026)$; glucose monitoring $(\mathrm{r}=0.319 ; p=0.000)$; compliance with medication $(\mathrm{r}=0.438 ; \mathrm{p}=0.00)$; risk reduction $(\mathrm{r}=$ 
$0.229 ; p=0.012)$ However, patient perception is not correlated with foot care $(\mathrm{r}=0.052$; $p=0.575)$ (See table 4 below).

\section{DISCUSSION}

This study assessed the perception of self-care and self-care practice of diabetic patients attending selected hospitals in Oyo State, Nigeria. Most of the respondents had moderate perception of self-care. The result showed that respondents' view of type- 2 diabetics resulted in careful overall self-care behaviour. The respondent's perception of self-care significantly influences self-care practices. This finding is also consistent with previous findings that showed that diabetes perception significantly influenced self-care practices among persons living with type-2 diabetes (Alzubaidi et al., 2015; Sharry, Moss-Morris, Kendrick.2011). On the contrary, Eknithiest (2018) has reported a different finding regarding, perception, and practice about type 2 diabetes mellitus among patients where it was not significant. This is logical because the respondent's view about an illness will invariably affect their practice. Also, the result showed a positive correlation between perception and the domain specific diabetes self-care practices such as respondents' physical activities, glucose monitoring and compliance to medication, and a negative correlation to healthy eating. This is consistent with earlier finding by Broadbent et al., (2011) that patients' diabetes perceptions influence their adherence to medication, diet and exercise significantly. The findings from the current findings have implications for the involvement of psychologists in the delivery of diabetes care as the cognitive and emotional representation of the illness by the patients could pose a great challenge to their engagement in diabetes self-care practices especially within the dietary and exercise domains.Respondent's perception of self-care is influenced by gender, education, ethnicity, occupational status and family history of diabetes. This finding is consistent with the finding of Melkamu, Berhe \& Simegnew (2021).

Most of the respondents had low self-care practices; this finding is similar to the findings of Al-Maskari et al., (2013) and Melkamu, Berhe \& Simegnew (2021). The most commonly achieved domain-specific self-care activities in this study were compliance with medication, which is consistent with previous studies (Bonger, Shiferaw, \& Tariku, 2018; Tewahido \&Berhane 2017). Higher levels of compliance with medication, as reported previously, could be due to the patient's perception that taking medication is an easier way to manage their illness and essential for their survival (Tewahido \& Berhane 2017). Diabetes patients in the current study demonstrated a poor level of monitoring their blood glucose which is also consistent with previous reports (Gurmu, Gela, \& Aga, 2018; Tewahido \& Berhane 2017).

The findings from this study have some practical implications for diabetes healthcare delivery. Firstly, the significant associations found between perception and self-care practices suggests that there is the need to train healthcare providers to address the chronic care needs of persons with diabetes. Secondly, nurses and doctors should be equipped with resources to address the self-care needs of patients with diabetes in the form of information leaflets and other relevant materials to aid independent self-care. Such self-care information should include information on causes, prognosis and management strategies. Finally, since group education is generally practiced at the various diabetes units, it is recommended that individual needs should also be taken into consideration due to variations in educational levels and interpretation of the educational materials. 
The study has certain limitations such as: this is hospital-based study done in cross-sectional design. It cannot be generalized to the general population as only people in a certain spectrum of disease can be available at hospital settings and causal associations cannot be made. Second, there are potential confounding factors that were not controlled for in the study such as social support.

\section{CONCLUSION}

The findings from this current study suggest that diabetes self-care practices of persons living with type- 2 diabetes in Oyo state are significantly influenced by their perception. Therefore, measures should be put in place to increase patients' perception of self-care and also, healthcare practitioners should understand that how patients interpret their self-care is very significant in determining whether they will follow the recommended self-care practices or not.

\section{REFERENCES}

Al-Maskari, F., El-Sadig, M., Al-Kaabi, J., Afandi, B., Nagelkerke, N., \&Yeatts, K.(2013). Knowledge, attitude and practices of diabetic patients in the United Arab Emirates. PLoS One, 8(1), e52857.

Alzubaidi, H., McMamara, K., Chapman, C., Stevenson, V.,\& Marriott J. (2015). Medicinetaking experiences and associated factors: comparison between Arabic-speaking and Caucasian English-speaking patients with Type 2 diabetes. Diabetes Medicine, 32,$12 ; 1625-33$.

American Diabetes Association Standards of Medical Care in Diabetes (2009).Diabetes Care,;32(Suppl 1):S13-S61

Aminde, L. N., Tindong, M., Ngwasiri, C. A., Aminde, J. A., Njim, T., Fondong, A. A., \&Takah, N. F. (2019). Adherence to antidiabetic medication and factors associated with non-adherence among patients with type-2 diabetes mellitus in two regional hospitals in Cameroon. BMC Endocrine Disorders, 19(1), 35

Bonger, Z., Shiferaw, S., \& Tariku, E. (2018). Adherence to diabetic self-care practices and its associated factors among patients with type 2 diabetes in Addis Ababa, Ethiopia. Patient Prefer Adherence, 12; 963-970.

Broadbent, E., Donkin, L., \&Stroh, J. (2011).Illness and treatment perceptions are associated with adherence to medications, diet, and exercise in diabetic patients.Diabetes Care, 34,$2 ; 338-40$.

Dahiru, T., Aliyu, A.A.,\&Shehu,A.U. (2016). A review of population-based studies on diabetes mellitus in Nigeria.Sub-Saharan African Journal of Medicine, 3(2), 59-64. https://doi.org/10.4103/2384-5147.184351

Eknithiset, R., Samrongthong, R., \&Kumar R.(2018). Factors Associated With Knowledge, Perception, And Practice Toward Self-Care Among Elderly Patients Suffering From Type 2 Diabetes Mellitus In Rural Thailand. Journal of Ayub Medical College Abbottabad, 30,1; 107-10. Epub 2018/03/06.. 
Elsous, A., Radwan, M., Al-Sharif, H., \& Abu Mustafa, A. (2017). Medications Adherence and Associated Factors among Patients with Type 2 Diabetes Mellitus in the Gaza Strip, Palestine. Frontiers in Endocrinology, 8, 100

Gurmu, Y., Gela, D., \&Aga, F. (2018). Factors associated with self-care practice among adult diabetes patients in West Shoa Zone, Oromia Regional State, Ethiopia. BMC Health Service Research, 18,1;732.

International Diabetes Federation. IDF Diabetes Atlas, 9th ed. Brussels, Belgium: International Diabetes Federation; 2019

Kassahun, T., Gesesew, H., Mwanri, L., \&Eshetie, T. (2016). Diabetes related knowledge, self-care behaviours and adherence to medications among diabetic patients in Southwest Ethiopia: a cross-sectional survey. BMC Endocrine Disorders, 16(1), 28.

Kolb, H., \& Martin, S. (2017). Environmental/lifestyle factors in the pathogenesis and prevention of type 2 diabetes. BMC medicine, 15(1), 131.https://doi.org/10.1186/s12916-017-0901-X

McSharry, J., Moss-Morris, R., \&Kendrick T. (2011). Illness perceptions and glycaemic control in diabetes: a systematic review with meta-analysis. Diabetes Medicine, 28,$11 ; 1300-10$.

Melkamu, L., Berhe, R., \&Handebo, S. (2021). Does Patients' Perception Affect Self-Care Practices? The Perspective of Health Belief Model. Diabetes Metabolic Syndrone Obesity, 14:2145-2154.https://doi.org/10.2147/DMSO.S306752

Mogre, V., Abanga, Z. O., Tzelepis, F., Johnson, N. A., \& Paul, C. (2017). Adherence to and factors associated with self-care behaviours in type 2 diabetes patients in Ghana. BMC Endocrine Disorders, 17(1), 20.

Odeyinka, O., \&Ajayi, I. (2017).Prevalence of hypertension and diabetes and their determinants among commercial drivers in Ibadan metropolis, South-Western Nigeria. Nigerian Journal of Cardiology, 14, 75 83.https://doi.org/10.4103/njc.njc_11_17

Oluma, A., Mosisa, G., Abadiga, M., Tsegaye, R., Habte, A., \&Abdissa, E. (2020).Predictors of Adherence to Self-Care Behavior among Patients with Diabetes at Public Hospitals in West Ethiopia. Diabetes, Metabolic Syndrome and Obesity: targets and therapy, 13, 3277-3288

Patterson, C. C., Harjutsalo, V., Rosenbauer, J., Neu, A., Cinek, O., Skrivarhaug, T., RamiMerhar, B., Soltesz, G., Svensson, J., Parslow, R. C., Castell, C., Schoenle, E. J., Bingley, P. J., Dahlquist, G., Jarosz-Chobot, P. K., Marčiulionytė, D., Roche, E. F., Rothe, U., Bratina, N., Ionescu-Tirgoviste, C., ... Green, A. (2019). Trends and cyclical variation in the incidence of childhood type 1 diabetes in 26 European centres in the 25 year period 1989-2013: a multicentre prospective registration study. Diabetologia, 62(3), 408-417. https://doi.org/10.1007/s00125-018-4763-3

Rasaki, S.O., Kasali, F.O., Biliaminu, S., Odeigah, L., Sunday, A.A., Sule, A., \&Musah, Y. (2017). Prevalence of diabetes and pre-diabetes in Oke-Ogun region of Oyo State, Nigeria. Cogent Medicine, 4(1).https://doi.org/10.1080/2331205X.2017.1326211 
Shrivastava, S. R., Shrivastava, P. S., \&Ramasamy, J. (2013). Role of self-care in management of diabetes mellitus. Journal of Diabetes and Metabolic Disorders, 12(1), 14

Tewahido, D, \&Berhane, Y. (2017) Self-care practices among diabetes patients in Addis Ababa: a qualitative study. PLoS ONE, 121; e0169062.

Wabe, N., Angamo, M., \&Hussein, S.(2011). Medication adherence in diabetes mellitus and self-management practices among type-2 diabetics in Ethiopia. North American Journal Medical Sciences, 3,9; 418-423.

World Health Assembly.Follow-up to the Political Declaration of the High-level Meeting of the General Assembly on the Prevention and Control of Non-communicable Diseases. Geneva: World Health Organization; 2013. 


\section{APPENDIX}

Table 1: Respondents Perception Of Self-Care Behaviour

\begin{tabular}{|l|l|l|}
\hline \multirow{2}{*}{ Variable } & Respondents in this study; N=120 mean scoreof30.68 $\pm \mathbf{7 . 5 6}$ \\
\cline { 2 - 3 } & Frequency & Percentage (\%) \\
\hline Low (0-26) & 35 & 29.2 \\
\hline Moderate(27-52) & 85 & 70.8 \\
\hline
\end{tabular}

Table 2 Relationship between Respondents Socio-demographic Characteristics and Perception of Self-care

\begin{tabular}{|c|c|c|c|c|}
\hline \multirow{2}{*}{$\begin{array}{l}\text { Socio-demographic variables for } \\
\text { consideration }\end{array}$} & \multicolumn{2}{|c|}{ Perception of Self-care $n=120$} & \multirow[t]{2}{*}{$\mathrm{X}^{2}$} & \multirow[t]{2}{*}{ p-value } \\
\hline & Low $(\%)$ & Moderate (\%) & & \\
\hline $\begin{array}{l}\text { Age (in years) } \\
42-47 \\
48-53 \\
54-59 \\
60-65 \\
66-71 \\
72-77 \\
78-83\end{array}$ & $\begin{array}{l}0(0) \\
4(25.0) \\
13(31.0) \\
3(15.0) \\
9(39.1) \\
6(40.0) \\
0(0)\end{array}$ & $\begin{array}{l}3(100) \\
12(75.0) \\
29(69.0) \\
17(85.0) \\
14(60.9) \\
9(60.0) \\
1(100)\end{array}$ & 5.74 & 0.45 \\
\hline $\begin{array}{l}\text { Gender } \\
\text { Male } \\
\text { Female }\end{array}$ & $\begin{array}{l}30(38.0) \\
5(12.2)\end{array}$ & $\begin{array}{l}49(62.0) \\
36(87.8)\end{array}$ & 8.63 & 0.003 \\
\hline $\begin{array}{l}\text { Educationalattainment } \\
\text { Non-Formal } \\
\text { Primary School } \\
\text { Secondary School } \\
\text { University Education }\end{array}$ & $\begin{array}{l}5(17.2) \\
13(22.4) \\
17(56.7) \\
0(0)\end{array}$ & $\begin{array}{l}24(20.5) \\
45(77.6) \\
13(43.3) \\
3(100)\end{array}$ & 15.49 & 0.001 \\
\hline $\begin{array}{l}\text { Ethnicity } \\
\text { Yoruba } \\
\text { Igbo } \\
\text { Hausa } \\
\text { Others } \\
\end{array}$ & $\begin{array}{l}3(23.1) \\
31(42.5) \\
1(3.4) \\
0(0)\end{array}$ & $\begin{array}{l}10(76.9) \\
42(57.5) \\
28(96.6) \\
5(100) \\
\end{array}$ & 17.82 & 0.00 \\
\hline $\begin{array}{l}\text { Occupational status } \\
\text { Employed full Time } \\
\text { Employed Part Time } \\
\text { Currently Unemployed } \\
\text { Retired from Active Employment } \\
\end{array}$ & $\begin{array}{l}7(11.7) \\
0(0) \\
16(51.6) \\
12(60.0)\end{array}$ & $\begin{array}{l}53(88.3) \\
9(100) \\
15(48.4) \\
8(40.0) \\
\end{array}$ & 29.36 & 0.000 \\
\hline $\begin{array}{l}\text { Doyouhaveafamilyhistoryofdiabetes? } \\
\text { Yes } \\
\text { No }\end{array}$ & $\begin{array}{l}13(19.7) \\
22(40.7)\end{array}$ & $\begin{array}{l}53(80.3) \\
32(59.3)\end{array}$ & 6.36 & 0.01 \\
\hline
\end{tabular}


Table 3: Respondents Self-Care Practices

\begin{tabular}{l|l|l|l|}
\hline \multicolumn{1}{l}{ Self-care sub-domain } & \multicolumn{1}{l}{ Low (\%) } & \multicolumn{1}{l}{ High (\%) } & \multicolumn{1}{l}{ Mean } \\
\hline \multicolumn{1}{l}{ Physical activities } & $114(95.0)$ & \multicolumn{1}{l}{$6(5.0)$} & \multicolumn{1}{l}{$4.13 \pm 1.36$} \\
\hline Healthy eating & $102(85.0)$ & $18(15.0)$ & $4.96 \pm 1.55$ \\
\hline Blood glucose monitoring & $116(96.7)$ & $4(3.3)$ & $4.09 \pm 1.73$ \\
\hline Compliance with medication & $87(72.5)$ & $33(27.5)$ & $5.92 \pm 3.31$ \\
\hline Risk reduction behaviour & $93(77.5)$ & $27(22.5)$ & $6.31 \pm 1.96$ \\
\hline Foot care behaviour & $70(58.3)$ & $50(41.7)$ & $7.21 \pm 2.55$ \\
\hline Overall Self-care behaviour & $113(94.2)$ & $7(5.8)$ & $32.6 \pm 6.24$ \\
\hline
\end{tabular}

Table 4 Relationship between Perception and Practice of Self-care

\begin{tabular}{|l|l|l|}
\hline \multicolumn{1}{l}{ Variable } & \multicolumn{2}{l}{ Perception N=120 } \\
\cline { 2 - 3 } \multicolumn{1}{l|}{} & $\mathrm{R}$ & $\mathrm{p}$-value \\
\hline Self-care & 0.404 & 0.000 \\
\hline Physical activities & 0.184 & 0.004 \\
\hline Healthy eating & -0.24 & 0.026 \\
\hline Glucose Monitoring & 0.319 & 0.000 \\
\hline Compliance to medication & 0.438 & 0.000 \\
\hline Risk reduction & 0.229 & 0.012 \\
\hline Foot care & 0.052 & 0.575 \\
\hline
\end{tabular}

